\title{
PROGRAMA DE CONCESSÃO DE RODOVIAS EM SÃO PAULO E NOVOS AGENTES ECONÔMICOS DO PERÍODO CONTEMPORÂNEO. UMA LEITURA GEOGRÁFICA DO PLANEJAMENTO GOVERNAMENTAL E DOS REPASSES DE ISSQN AOS PEQUENOS MUNICÍPIOS
}

Fabricio Gallo

UNESP - Universidade Estadual Paulista "Júlio de Mesquita Filho", Depto. de Geografia e Planejamento Ambiental, Rio Claro, SP, Brasil

fabricio.gallo@unesp.br

\begin{abstract}
RESUMO
Busca-se iniciar uma reflexão acerca do papel do Estado brasileiro como agente significativo no processo de uso do território no período atual. O que se verificou foi a mudança do papel do Estado, atuando agora como regulador e não mais como provedor de alguns serviços, através de privatizações, concessões e PPPs. Como compromisso analítico é sugerido um estudo das práticas de concessão de rodovias que ganharam espaço ao longo das últimas décadas. Um aspecto relevante visa entender a relevância fiscal da implantação das praças de pedágio para os municípios do estado paulista já que segundo estabelecido pelos contratos de concessão, as empresas concessionárias são obrigadas a repassar $5 \%$ do valor bruto de suas receitas com pedágio para os munícipios. Esse repasse se dá pela forma de Imposto Sobre Serviço de Qualquer Natureza (ISSQN), tendo direito a receber aqueles municípios cuja rodovia concessionada cruza seu território. Neste texto analisamos os municípios que recebem repasses oriundos da concessão rodoviária administrada pela empresa Entrevias S.A.
\end{abstract}

Palavras-chave: Concessão de rodovias. Território usado. Planejamento territorial. Estado de São Paulo. Pequenos municípios.

\section{HIGHWAY CONCESSION PROGRAM IN SÃO PAULO AND NEW ECONOMIC AGENTS OF THE CONTEMPORARY PERIOD. A GEOGRAPHIC READING OF GOVERNMENT PLANNING AND ISSQN TRANSFERS TO SMALL MUNICIPALITIES}

\begin{abstract}
The purpose of this article is to reflect on the role of the Brazilian state as a significant agent in the current use of territory process. A change in the role of the state, which now acts as a regulator and no longer as a provider of some services on account of privatizations, concessions and PPPs, has been observed. A study of highway concession practices that have gained space over the last decades is subject to analysis. One relevant aspect to consider is the fiscal relevance of the implemented toll plazas for the state of São Paulo's municipalities since according to the concession contracts the concessionaire companies are required to pass $5 \%$ of the gross value of their toll revenues to municipalities. This transfer is processed as a "tax on service of any nature" (ISSQN), having the right to receive those municipalities whose highway concessionaire crosses its territory. In this paper we analyze the municipalities receiving transfers coming from road concession administered by the company Entrevias S.A.
\end{abstract}

Keywords: Concession of highways. Used territory. Territorial planning. State of São Paulo. Small municipalities.

\section{INTRODUÇÃO}

Partimos do entendimento de que o território brasileiro é o produto e a condição de uma difusão seletiva do meio técnico-científico-informacional e que para buscarmos a compreensão de como o território é usado (SANTOS, 1994, 2002) no período contemporâneo, verifica-se a necessidade de identificar os poderes que têm os distintos agentes neste processo. No que tange ao uso do território, Santos (2002) identifica agentes que têm poder de ação sobre o território como um todo (os agentes hegemônicos) e aqueles cujo poder é mais limitado espacial e temporalmente, estes são os agentes não-hegemônicos. Para estes últimos o território seria seu abrigo, já para os primeiros o território seria um recurso

$\begin{array}{lllll}\text { Caminhos de Geografia } \quad \text { Uberlândia-MG } & \text { v. 21, n. } 77 \quad \text { Out/2020 } & \text { p. 165-179 Página } 165\end{array}$


Programa de concessão de rodovias em São Paulo e novos agentes econômicos do período contemporâneo. Uma leitura geográfica do planejamento governamental e dos repasses de ISSQN aos pequenos municípios

(GOTTMANN, 2012). Na leitura de Silveira (2011, p. 81), objetos técnicos e normas que animam estes objetos nos chegam do passado, um espaço herdado, "mas como as ações presentificam, trazem novos conteúdos e criam novas resistências, um gerúndio é de rigor: território sendo usado. Nesse sistema de ações, o futuro se instala e o território se torna, ainda mais, um híbrido"

Acreditamos que um dos agentes mais significativo no exercício do poder de uso do território é o Estado, pois para este exercício são necessários meios para fazê-lo e este é o agente que organiza o território através de seu poder de regulação do dinheiro, dos financiamentos, da lei e da política. No entanto, faz-se conveniente salientar o alerta de Cataia (2013, p. 1146) de que muitas fontes do poder não se localizam somente no interior das instituições do Estado. Este autor ressalva para não se cometer o erro, apontado por Raffestin (1993), de interpretar o Estado como a única fonte.

\begin{abstract}
Essas outras fontes do poder - ou, seria melhor dizer, que disputam o poder - incluem os agentes hegemônicos - como as grandes empresas - e os agentes não hegemônicos, que incluem a grande maioria dos movimentos sociais e todos aqueles que, não organizados na forma de "movimentos sociais", são invisibilizados pelos agentes hegemônicos (CATAIA, 2013, p. 1146).
\end{abstract}

Antas Jr. (2005) nos lembra que no período atual, caracterizado pelo processo de saída do Estado de alguns setores por meio de privatizações e concessões de serviços públicos ao capital privado, encontramos elementos de uma regulação híbrida do território, já que, mesmo depois das privatizações e concessões o Estado permanece em seu papel regulador, conforme aos mecanismos tradicionais, mas a partir da criação de novos mecanismos de regulação para estes setores e que pode determinar uma regulação do território com forte direcionamento para a lógica de mercado (o autor cita, como exemplo, a criação das Agências Estaduais e Nacionais de Regulação: ARTESP, ANATEL, ANEEL, ANP, ANS, ANVISA etc.).

Para Limonad (2014, p.8) o Estado pode ser entendido, simultaneamente, como o resultado e arena de interação de forças e de interesses sociais que podem ser diversos e contraditórios, por isso

\begin{abstract}
sua forma institucional é uma resultante e um condicionante, da correlação de forças e das estratégias dos diferentes atores sociais e políticos, onde as forças hegemônicas fazem valer suas estratégias inscritas territorialmente e articuladas em diferentes escalas, estratégias estas selecionadas de forma seletiva em conformidade com as alianças prevalecentes no bloco do poder.
\end{abstract}

Concordamos, ainda, com a visão da mesma autora de que se evidencia no Brasil, cada vez mais, o papel do Estado no processo de criação de condições gerais para a acumulação de diferentes capitais. Para ela, no país "o Estado assumiu e segue assumindo o papel de promotor, financiador e parceiro de diferentes capitais. O que tem levado a um fortalecimento de distintos grupos de interesse localizados" (LIMONAD, 2014, p. 12). Esta visão se completa com a afirmação de Pinto e Balanco (2014) de que o Estado representa a combinação, em diferentes graus, e determinada por uma conjuntura espacial e temporal, de dois grandes eixos: autonomia da administração central versus subordinação do Estado a determinados interesses.

De acordo com Cataia (2013, p. 1144) o território usado teria centralidade no debate federativo já que "o território seletivamente usado tensiona a política, desarmoniza antigos pactos e condiciona a ação política. Ele tem um papel ativo na constituição dos pactos sociais, daí poder-se falar em pactos socioterritoriais". Desta forma, segundo o autor, num "movimento dialético, o território ativo condiciona a ação política, ao mesmo tempo em que as políticas públicas reconfiguram o território" (CATAIA, 2013, p. 1144).

Em outra oportunidade propusemos a reflexão de que uma relação sistêmica se instala para a viabilidade dos diversos projetos de uso do território pelos distintos agentes - sobretudo por aqueles com maior poder de ação. De um lado as empresas, corporações e agentes privados buscam no Estado o recurso, o dinheiro público, o instrumental normativo e legislativo favorável para o desenvolvimento e viabilidade de seus projetos, afinal é o Estado aquele que fornece infraestruturas produtivas e de escoamento de produção; capital de giro, financiamentos e empréstimos em programas de desenvolvimento econômico (por muitas vezes subsidiados); flexibilização normativa (produtiva, trabalhista, ambiental, etc.) para estimular a competitividade em escalas local, nacional e global. De outro lado, uma elite se instala, se apodera do aparelho estatal e, a partir deste instrumento, se mantém como classe dominante (GALLO, 2017).

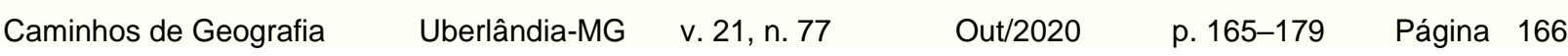


Programa de concessão de rodovias em São Paulo e novos agentes econômicos do período contemporâneo. Uma leitura geográfica do planejamento governamental e dos repasses de ISSQN aos pequenos municípios

Acreditamos ser possível dizer que um sistema de usos do território se instala já que uma relação de mutualidade se realiza, isto é, o processo de uso do território não se realiza de forma isolada por um ou outro agente, já que uma complexa rede de articulações (lícitas ou não, visíveis ou não) acaba por se estabelecer e, em muitas, o Estado está presente - direta ou indiretamente. As corporações, instituições e agentes privados hegemônicos, para usar o território dependem da base do Estado para viabilizar e concretizar seus projetos; ao mesmo tempo, para se manter como elite dominante (que se efetiva através do constante apoio do capital privado), a fração de classe que está no comando do Estado, atende aos interesses desses agentes corporativos através do aparato estatal. No âmbito deste complexo jogo de alianças e articulações entre estes agentes, aqueles que não são hegemônicos (ou que não conseguem se manter como hegemônicos) acabam excluídos dos processos decisórios.

Voltando nosso debate para a compreensão das articulações entre o Estado brasileiro e os agentes econômicos no período atual, propomos refletir como que a arquitetura de nosso sistema federativo permite a instalação de complexas articulações que viabilizam um sistema de usos do território onde os projetos privados e estatal se desenvolvem mutuamente. Esta é uma das maneiras pela qual é praticada a política das empresas (SANTOS, 1997), já que a gestão e regulação do território são cada vez mais críticos porque as instâncias econômicas têm muito poder de interferência.

A evolução do federalismo brasileiro (fruto da influência e do poder das elites, dos diferentes textos constitucionais elaborados e das distintas competências atribuídas aos entes) aponta uma das formas de como o Estado brasileiro usa o território para efetivar o exercício do poder. Para esta tarefa, propõese compreender o território usado através da ótica do Estado, sobretudo destacando o entendimento de que na República Federativa do Brasil os três níveis da Federação (União, Estados-membros e os Municípios) são "Estado" e que a esses três níveis de governo são assegurados autonomia e competências legiferantes e administrativas, já que o princípio federativo parte da premissa de que todos são iguais entre si. Além da isonomia entre os entes, a Constituição Federal de 1988 Ihes garantiu autonomia e competências exclusivas (inclusive tributária) para tratar de determinados assuntos, estabelecidos constitucionalmente como próprios a cada ente.

Cataia (2013, p. 1145-1146) nos alerta que, de certa maneira, temos que reconhecer que a Federação (sinônimo de poder público) deve ser entendida como "um sistema de ação e cada um de seus membros (União, estados e municípios) como subsistemas do sistema de ação federativo, cada um tendo sua esfera própria de ação. Assim, cada ente da Federação é um subsistema do sistema de ação federativo". Este autor ainda nos indica que

cada ente da Federação é um subsistema do sistema de ação federativo e em cada um deles orbitam "poderes periféricos" ou "poderes laterais" (GRÉMION, 1976; SASSEN, 2010) e "elites do poder" (MILLS, 1962; BURZTYN, 1987; CASTRO, 1992; FAORO, 2000), que, apesar de não serem membros da estrutura hierárquica interna de cada ente da Federação, fazem parte do sistema, porque têm poder para interferir na regulação e execução da renovação das materialidades, redesenhando assim a divisão do trabalho local" (2013, p. 1146)

A manutenção do equilíbrio de poder entre as esferas federativas - necessária devido a existência de dissimetrias econômicas -, impõe constantemente pactos e negociações políticas entre os entes dos diferentes níveis e entre estes com o poder econômico privado. Sugere-se que do ponto de vista federativo não se pode compreender as dinâmicas locais sem uma mais justa compreensão das articulações entre as escalas de poder. Como aponta Vainer (2006, p. 28) "o poder, mais do que nunca [...] está na capacidade de articular escalas, de analisar e intervir de modo transescalar". Isso corrobora a assertiva de Harvey (2005) para quem a atenção não deve ser dirigida apenas ao governo local, pois o poder de organização da vida de uma cidade muitas vezes está em outra parte, em coalizões de forças mais amplas, em que o governo e administração locais desempenham apenas papel facilitador e coordenador.

\section{OS PROGRAMAS DE CONCESSÃO DE RODOVIAS E OS NOVOS AGENTES DO PERÍODO CONTEMPORÂNEO.}

Como compromisso analítico para este trabalho - e buscando interpretar as articulações entre os entes federados e o capital privado na viabilização de um processo sistêmico de usos do território - é sugerida a análise das concessões de rodovias à iniciativa privada no estado de São Paulo.

Essas concessões iniciam-se no governo de Mário Covas (1995-2001), com a justificativa dos custos elevados que as rodovias geravam aos cofres públicos à época. Simultaneamente, cumprindo seu papel neoliberal de regulador e fiscalizador, São Paulo cria a Comissão de Monitoramento das

$\begin{array}{lllll}\text { Caminhos de Geografia } & \text { Uberlândia-MG } & \text { v. 21, n. } 77 & \text { Out/2020 } & \text { p. 165-179 Página } 167\end{array}$


Programa de concessão de rodovias em São Paulo e novos agentes econômicos do período contemporâneo. Uma leitura geográfica do planejamento governamental e dos repasses de ISSQN aos pequenos municípios

Concessões e Permissões de Serviços Públicos, ainda em 1998, com a função de acompanhar os processos que ocorriam sobre o transporte. Esta funcionou em caráter temporário e foi sucedida pela Agência Reguladora de Serviços Públicos Delegados de Transporte do Estado de São Paulo (ARTESP), criada em 2002, para regulamentar e fiscalizar todos os serviços públicos de transporte autorizados, permitidos ou concedidos à iniciativa privada.

De acordo com informações disponíveis em São Paulo (2016), Machado (2005) e Oliveira (2016), a primeira etapa de concessões ocorreu em 1998, com a concessão de 12 lotes, totalizando mais de $3.500 \mathrm{~km}$ de rodovias repassadas à iniciativa privada. Foram vencedoras do processo de concessão 12 empresas - AutoBAn, TEBE, Vianorte, Intervias, Centrovias, Triângulo do Sol, Autovias, Renovias, ViaOeste, Rodovias das Colinas, SPVias e Ecovias dos Imigrantes - que inicialmente teriam seu contrato estipulado em 20 anos, porém, algumas chegaram a estendê-lo por 28 anos. A segunda etapa de concessões começou em 2007 e se estendeu até 2011, repassando lotes para mais 7 empresas, um acréscimo de $2.700 \mathrm{~km}$. Para as novas empresas - Rota das Bandeiras, CART, ViaRondon, Rodovias do Tietê, Ecopistas, Rodoanel Oeste e SPMar - foi estabelecido o critério de menor valor de tarifa de pedágio ofertada, também com pagamento de ônus fixo ao Estado e com prazo de 30 anos, chegando a 35 anos no caso da SPMar.

Segundo Oliveira (2016), o movimento de concessões das rodovias paulistas permanece ativo, com a terceira etapa em processo. Uma das mais recentes empresas a vencer uma licitação para concessão de rodovias foi a Concessionária Tamoios, iniciando suas operações em abril de 2015. Conforme ARTESP (2014), trata-se de uma Parceria Público-Privada (PPP), que se enquadra no modelo de concessão patrocinada, na qual o retorno do investimento feito pela empresa via tarifas cobradas dos usuários é insatisfatório, assim sendo, o poder concedente complementa a remuneração através de pagamentos diretos regulares - as chamadas contraprestações do poder público. A extensão total de rodovias sob controle da Concessionária Tamoios atinge pouco mais de $119 \mathrm{~km}$ e é lindeira aos municípios de São José dos Campos, Jambeiro, Jacareí, Paraibuna e Caraguatatuba. Em novembro de 2015, o então governador Geraldo Alckmin assinou o decreto que autorizava a concessão de mais 4 lotes de rodovias (os chamados Lotes A, B, C e D), conforme a figura 1 (excerto da apresentação "Novas Concessões de Rodovias Estaduais de São Paulo", realizada pelo governo do estado de São Paulo em Audiência Pública do dia 26 de janeiro de 2016).

Figura 1 - São Paulo. Estrutura de concessões de rodovias em São Paulo (lotes A, B, C e D), 2016.

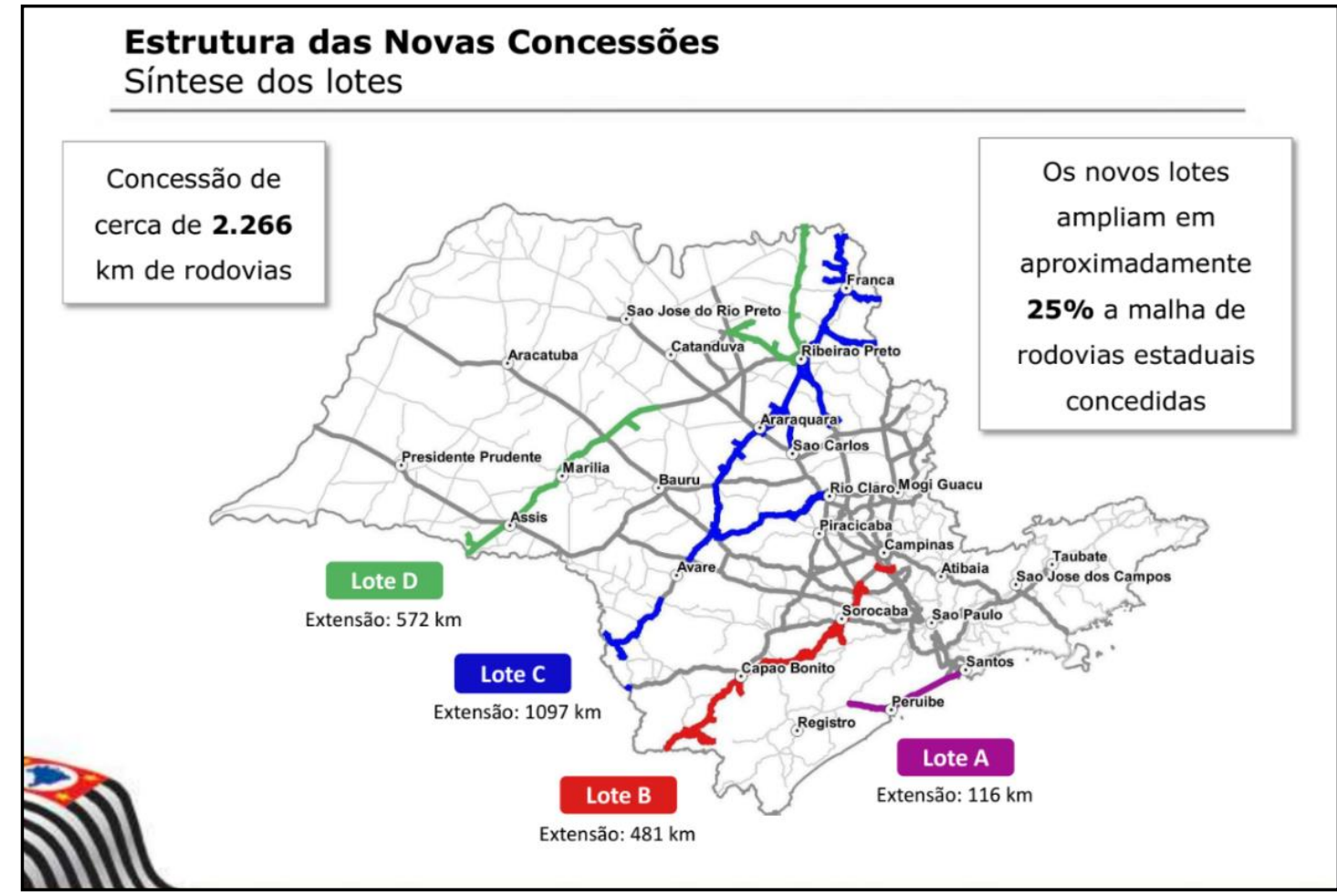

Fonte - São Paulo (2016). 
Programa de concessão de rodovias em São Paulo e novos agentes econômicos do período contemporâneo. Uma leitura geográfica do planejamento governamental e dos repasses de ISSQN aos pequenos municípios

O processo de leilão era para ser bem rápido, isto é, segundo o governo do estado de São Paulo entre janeiro e fevereiro de 2016 seriam realizadas Audiências Públicas, em seguida, entre fevereiro e abril de 2016 seria disponibilizada à Consulta Pública os documentos pertinentes e por fim, em abril de 2016, teria início a publicação dos editais. No entanto, neste caso, nem todos os leilões foram realizados. Apenas os leilões dos lotes $C$ e $D$ foram adiante e tiveram as empresas vencedoras anunciadas.

Com ágio de $438,17 \%$ o grupo Arteris S.A. (joint venture entre o grupo espanhol Abertis - que atua na administração de rodovias em 15 países: Espanha, França, Chile, Brasil, Itália, Porto Rico, Argentina, Índia, Colômbia, Irlanda, Reino Unido, Canadá, Croácia, Hungria - e o fundo de investimentos canadense Brookfield) venceu o leilão do lote $C$ - Itaporanga-Franca. Este lote contempla $720 \mathrm{~km}$ que abrangem trechos de dez rodovias: SP-255, SP-249, SP-257, SP-281, SP-304, SP-318, SP-328, SP330, SP-334 e SP-345. E com ágio de 130,89\% o grupo Pátria Investimentos, por meio de seu Fundo de Investimentos em Infraestrutura III venceu o leilão do lote D - Florínea-Igarapava. Neste caso uma novidade se estabeleceu já que foi a primeira vez que um fundo de investimentos participa de uma licitação rodoviária no país. Convém apontar que conforme a Comissão de Valores Mobiliários (CVM), o funcionamento dos fundos de investimento configura um sistema de condomínio, uma vez que o patrimônio do fundo é compartilhado e pertence a vários cotistas ou investidores (CVM, 2014). O fundo de investimentos Pátria Infraestrutura III representa, no Brasil, o fundo de investimentos norteamericano Blackstone, um dos maiores do mundo. Por conta das distintas características deste novo player participante do processo de concessões de rodovias paulistas, a Comissão Especial de Licitação do governo do estado de São Paulo avaliou a documentação apresentada pelo grupo Pátria sob aspectos jurídicos, econômico-financeiros e técnicos e constatou que a licitante atendia a todos os requisitos estabelecidos em edital. Assim, em 04/04/2017 a ARTESP publicou no Diário Oficial do Estado a habilitação do Pátria Infraestrutura III - Fundo de Investimentos em Participações para operar, por meio de concessão, $570 \mathrm{~km}$ de rodovias paulistas. Este lote em questão engloba trechos de sete rodovias paulistas no eixo entre Florínea (divisa com o Paraná) e Igarapava (divisa com Minas Gerais): SP-266; SP-294; SP-322; SP-328; SP-330; SP-333 e SP-351.

O lote B previa a concessão de $481 \mathrm{~km}$ de rodovias entre as regiões do Alto Ribeira, Sorocaba e Campinas e se encontrava em fase de Audiências Públicas quando o então governador Geraldo Alckmin resolveu suspender o leilão deste lote, em fevereiro de 2016, por conta dos protestos das prefeituras e de moradores da região. Segundo eles, há tempos havia a promessa de duplicação de trechos de rodovias na região sem a instalação de praças de pedágio (TOMAZELA, 2016). Assim, mediante os protestos o leilão do lote foi suspenso.

Já o lote A - Rodovias Litoral Paulista não teve seu edital de concessão anunciado porque o trecho inicialmente previsto $(116 \mathrm{~km})$ foi incorporado a outro projeto maior, passaria a ter $232 \mathrm{~km}$ e englobaria a duplicação e melhoria das SP-055 e SP-098. Esta discussão fez parte da $230^{\mathrm{a}}$ e $235^{\mathrm{a}}$ Reuniões Ordinária do CDPED - Conselho Diretor do Programa Estadual de Desestatização (SÃO PAULO, 2018a, 2018b). Na 235 a reunião do CDPED, realizada em 06 de agosto de 2018, ficou decidido por unanimidade que a concessão do trecho "Rodovias Litoral Paulista" deveria permanecer "em estudo" já que passaria a fazer do Projeto "Macroanel Rodoviário Paulista" - um conjunto rodovias concedidas à iniciativa privada em São Paulo para viabilizar a mobilidade rodoviária no estado. Assim, os estudos sobre a potencialidade de concessão do trecho ficaram a cargo do Grupo de Trabalho, que já havia sido instituído pelo Decreto estadual oㅜ 63.489, de 14/06/2018. A função deste Grupo de Trabalho é

\begin{abstract}
promover estudos para o empreendimento denominado Macroanel Rodoviário Paulista, a fim de apresentar as alternativas de traçado com os respectivos riscos e os planos de ação para sua implantação pelo Governo do Estado de São Paulo, inclusive avaliando as possibilidades de celebração de Parcerias Público-Privadas para a realização do empreendimento (SÃO PAULO, 2018a).
\end{abstract}

Ao avaliarmos os dois lotes já concedidos ( $C$ e $D$ ), entendemos que no atual período os grupos internacionais de investimento (como é o caso dos fundos Brookfield atuando no lote $\mathrm{C}$ e Pátria Investimentos e Blackstone, operando no lote $\mathrm{D}$ ) podem impor estratégias e direcionamentos dos investimentos àqueles segmentos e setores mais "interessantes" ao mercado, ao mesmo tempo que mitigam os riscos de que o negócio acabe dando prejuízo ao adotar práticas de atuação por meio de 
Programa de concessão de rodovias em São Paulo e novos agentes econômicos do período contemporâneo. Uma leitura geográfica do planejamento governamental e dos repasses de ISSQN aos pequenos municípios

project finance, ou seja, para os fundos internacionais o risco é quase nulo ou muito baixo, já que segundo Borges (1998)

o project finance (...) se trata de uma engenharia de projeto estruturado para segregar o risco, preservar a capacidade de endividamento de seus empreendedores ou patrocinadores, dividir o risco entre vários interessados, economizar no pagamento de tributos, levar adiante um projeto grande demais para um só patrocinador ou evitar a necessidade de garantias reais, utilizando apenas a garantia de recebíveis do próprio projeto (fluxo de caixa autogerado).

A título de exemplo, para administrar o lote $\mathrm{D}$ de rodovias foi criada a empresa Entrevias, sendo que esta Companhia, à época de sua criação, tinha como única controladora direta a Infraestrutura Investimentos e Participações II S.A., que por sua vez tem como controlador o Fundo Pátria Infraestrutura III - Fundo de Investimento em Participações, um dos fundos administrados pelo grupo Pátria Investimentos - que é o segundo maior administrador de FIP-Fundos de Investimentos em Participações em patrimônio líquido administrado no Brasil, controlando pouco mais de $R$ \$ 34 bilhões em julho de 2020 (ANBIMA, 2020) - desde 01 de março de 2018 a Entrevias opera como Companhia aberta em Bolsa de Valores pois teve seu pedido de registro aceito na Comissão de Valores Mobiliários.

No caso das operações da concessionária Entrevias, esta afirmação de que o risco é quase nulo ou muito baixo pode ser observada pelas cláusulas $19^{\underline{a}}$ a $23^{\mathrm{a}}$ do contrato de concessão assinado entre o poder concedente e a concessionária e que tratam a temática dos riscos do negócio (ARTESP, 2017). Também pode ser observada pelo exposto no relatório da empresa de consultoria e avaliação de riscos FitchRatings (uma das maiores do mundo) que analisou as operações da Entrevias acerca da $2^{\text {a }}$ emissão de debêntures da empresa. Convém apontar que o papel destas agências de classificação de risco tem ganhado destaque nos últimos anos em função de sua posição estratégica nas negociações que envolvem os agentes econômicos globais. Importante debate sobre a ação de tais grupos pode ser encontrado em Silva Bernardes (2012) e Pasti e Silva Bernardes (2013). No documento, divulgado em fevereiro de 2019, a Fitch classificou esta emissão como "estável" com ratings "BB" e "AA(bra)" (FITCHRATINGS, 2019). O que chama atenção no relatório e que atesta o risco quase nulo ou muito baixo de que as operações da Entrevias possam dar prejuízos, está reproduzido abaixo. Segundo a agência:

\begin{abstract}
Ainda em 2018, as concessionárias de rodovias foram proibidas de cobrar pedágios sobre os eixos suspensos de veículos pesados em todo território nacional. A Entrevias obteve um reequilíbrio econômico-financeiro parcial relativo apenas ao ano de 2018 , quando foi isenta de pagar a outorga variável (3,0\% da receita de pedágio) e teve a verba de fiscalização reduzida para $1,5 \%$ da receita, de 3,0\%. Embora o reequilíbrio definitivo ainda não tenha sido assinado, o poder concedente já reconheceu que as concessionárias têm o direito ao reequilíbrio e está negociando com cada rodovia individualmente.
\end{abstract}

Os cenários da Fitch consideram que a liquidez da Entrevias não será materialmente afetada a médio e longo prazos, pois o poder concedente já reconheceu o desequilíbrio; a Entrevias já conseguiu um reequilíbrio parcial em 2018; e o contrato de concessão da companhia permite o reequilíbrio por extensão de prazo da concessão apenas após o nono ano, privilegiando outras formas de reequilíbrio que preservem a liquidez da concessionária. Entre estas, o aumento nas tarifas, a diminuição da outorga variável e demais taxas, pagamento em dinheiro etc. (FITCHRATINGS, 2019)

De acordo com o regramento constante do Edital e do Contrato de Concessão Onerosa, pela exploração do sistema rodoviário a Entrevias assumiu o compromisso de pagar ao estado de São Paulo a outorga fixa de $\mathrm{R} \$ 1.314 .501 .667,00$, paga em 2 parcelas atualizadas pelo IPCA/IBGE, tendo sido paga a primeira parcela em maio de 2017 no valor de $R \$ 960.522 .305,00$. Conforme regramento constante do Edital e do Contrato de Concessão Onerosa, a segunda parcela do montante residual (de $\mathrm{R} \$ 397.250 .648$, na data base março de 2016), deverá ser paga na data da assinatura do Termo de Transferência do Sistema Remanescente, que será corrigido monetariamente desde a data base do Contrato. Também deveriam ser pagos o valor da outorga variável correspondente a $3 \%$ das receitas bruta mensais auferidas pela concessionária (pedágio e acessórias) bem como, $3 \%$ sobre a mesma 
Programa de concessão de rodovias em São Paulo e novos agentes econômicos do período contemporâneo. Uma leitura geográfica do planejamento governamental e dos repasses de ISSQN aos pequenos municípios

base a título de taxa de fiscalização. No entanto, neste último caso, conforme o relatório da Fitch Ratings o estado de São Paulo abdicou de receber, temporariamente, parte desses repasses para garantir o equilíbrio financeiro da Entrevias.

Podemos dizer que o Estado tem, cada vez mais, atendido aos anseios dos grandes grupos e tornado os leilões de concessões de infraestruturas mais atrativos (prazos longos de concessão, altos índices de retorno para as empresas investidoras, garantias de equilíbrio financeiro frente às incertezas do negócio etc.), além de manter papel decisivo na estrutura normativa dos serviços concedidos a partir de suas potenciais participações e influência juntos a órgãos reguladores (tais como ARTESP, ANEEL etc.), reforçando com isso a regulação híbrida do território. Convém aqui trazer o apontamento de Boneti (2017, p. 11) de que existe uma estreita afinidade entre os projetos do Estado e os interesses das elites econômicas. Embora no plano local (nacional e estadual) exista uma correlação das forças políticas na definição de políticas públicas, envolvendo movimentos sociais e outras organizações da sociedade civil, a definição de políticas públicas também estaria condicionada aos interesses das elites global pela determinação dos laços econômicos próprios do modo de produção capitalista.

Faz-se relevante a busca, cada vez maior dentro dos estudos de planejamento territorial, do entendimento da participação desses grandes grupos empresariais neste novo momento de concessão de rodovias que se abre, já que muitas concessões no estado de São Paulo vencerão nos próximos anos e, muito provavelmente, novos editais serão lançados para a renovação das mesmas. Nota-se uma maneira de burlar um dos argumentos principais favoráveis ao modelo de concessão, de que ao término do contrato as benfeitorias realizadas serão entregues ao Estado sem que este precise ressarcir a empresa. Oliveira e Sposito (2007, p. 50), já alertavam sobre essa possibilidade de uma renovação de contratos de concessão, ao escreverem que os períodos da concessão se fixaram entre 20 e 25 anos, "Isso se ao término destes contratos o governo paulista não refazê-los para as mesmas rodovias e concessionárias".

Conforme reportagem de Mantoan e Fernandes (2015) para o jornal Valor Econômico, o envolvimento das maiores construtoras do país na Operação Lava-Jato, mais as mudanças que vêm ocorrendo nas regras de financiamentos do BNDES (através da implantação do PPI - Programa de Parcerias para Investimentos), tende a favorecer a presença de grupos estrangeiros na disputa por lotes de rodovias a serem concedidas e como, também, financiadores deste processo juntamente com o banco brasileiro (2017, p. 14). É por isso que começam a aparecer os fundos de investimento e de pensões internacionais ou disputando diretamente os leilões para se tornarem administradores dos contratos de concessão das rodovias (como foi o caso do Fundo de Investimentos Pátria Infraestrutura III), ou associados a outros grupos em holdings para disputar os leilões e prover o financiamento/investimento das futuras obras.

Todo este quadro ilustra muito bem algumas características distintivas da fase atual do capitalismo, quando o capital se mundializa e cada vez mais as finanças se tornam autônomas e universais; o que explica a dimensão colossal e não obstante crescente dos fundos de investimento como forma de garantir a reprodução ampliada do capital na economia global. Conforme apontamos, os fundos de investimentos crescem no Brasil de maneira muito acelerada, são dominados por grandes grupos, e há a predominância de operações que envolvem ativos financeiros de alta liquidez, principalmente através de títulos públicos.

Dentro deste contexto, todavia, há a sombra de uma nova dinâmica no mercado dos fundos de investimento no Brasil com crescente participação na área de infraestrutura. Para Lopes (2012, p. 93), isso ocorre porque os fundos vêm se deparando com crescentes dificuldades em alocar seus recursos; daí a oportunidade representada pelos investimentos em exploração no setor de infraestrutura, uma vez que

Parece haver clara convergência entre a demanda intensiva de capital, com potencial geração de receitas de longo prazo, característicos dos serviços de infraestrutura, e a expressiva capacidade de investimentos dos fundos de pensão, visando obter fluxo de caixa futuro atualizado por índices de inflação de varejo (LOPES, 2012, p. 93)

Enquanto trabalhos como os de Hohl (2012) e Fritzen (2017) corroboram essa tendência ao indicar a crescente participação de fundos em investimentos no setor de geração de energia elétrica no Brasil, 
Programa de concessão de rodovias em São Paulo e novos agentes econômicos do período contemporâneo. Uma leitura geográfica do planejamento governamental

nossas investigações preliminares indicam que há também uma crescente participação dos fundos no processo de concessão de rodovias no estado de São Paulo.

\section{OS PEQUENOS MUNICÍPIOS PAULISTAS E O ISSQN REPASSADO PELAS CONCESSIONÁRIAS DE RODOVIAS.}

Almejando entender a relevância tributária da implantação das praças de pedágio para os municípios paulistas e, com isso, o significado local (isto é, na escala do município) da participação destes grupos empresariais que vêm ganhando os editais de leilões no estado de São Paulo, esboçaremos um pequeno estudo dos repasses compulsórios de Imposto Sobre Serviço de Qualquer Natureza (ISSQN) às prefeituras lindeiras às rodovias pedagiadas.

Nossa pretensão neste texto volta-se, principalmente, à busca do entendimento da participação dessas concessionárias na reprodução do cotidiano das pequenas municipalidades paulistas, (isto é, aquelas com até 20.000 habitantes, conforme uma opção nossa para este trabalho). Faz-se conveniente indicar que até o presente momento não existe oficialmente uma definição para o que seja um "pequeno município" e qualquer exercício de conceituação (por tamanho de população, por extensão territorial, por arrecadação tributária etc.) não atende a requisitos oficiais, já que estes não existem legalmente. A título de informação, tramita no Senado Federal Brasileiro uma Proposta de Emeda à Constituição que visa conceituar "pequenos municípios", trata-se da PEC- $n^{\circ}$ 57, de 2016 e em agosto de 2020 ela estava pronta para ser debatida e deliberada no plenário (BRASIL, 2016).

Ribeiro e Toneto Júnior (2004), explicam que a partir de 2003 houve uma alteração na distribuição desse imposto entre os municípios lindeiros às rodovias. Anteriormente, $40 \%$ do valor do repasse era destinado aos municípios que apresentavam praças de pedágio em seu território, os outros $60 \%$ eram divididos entre aqueles em que as rodovias apenas os cruzavam, proporcionalmente à quilometragem de rodovias concessionadas perpassando seus limites. A partir de julho de 2003, essa divisão foi alterada de maneira que a totalidade do repasse fosse transferida aos municípios, apenas segundo a quilometragem de rodovias presentes nestes, retirando o privilégio de valores mais elevados aos municípios com praças de pedágio.

Entende-se que este valor é mais relevante em munícipios menores e com menor dinamismo econômico, visto que sua fonte de recursos é muito mais limitada, arrecadando valores muito inferiores com tributos exclusivamente municipais (tais como Imposto Predial e Territorial Urbano - IPTU; Imposto sobre a Transferência de Bens Imóveis - ITBI e Imposto Sobre Serviços de Qualquer Natureza ISSQN, por exemplo). No caso dos grandes munícipios, com arrecadação através de diversos impostos entender e aplicados sobre uma população em número elevado, os repasses provenientes das concessionárias de rodovias pode se tornar pouco significante. Porém, nos municípios menores este repasse pode corresponder a uma porcentagem considerável de suas receitas orçamentárias. Outro ponto "positivo" com este imposto, sobretudo para os governantes municipais, é que a cobrança do pedágio se aplica em grande medida a não-residentes, ou seja, o grande volume de dinheiro não é retirado dos munícipes, não causando nenhum "prejuízo político" para os grupos políticos locais.

Para fins analíticos, exploraremos os desdobramentos do leilão do lote Florínea-Igarapava (Rodovias do Centro-Oeste Paulista, que compreende $570 \mathrm{~km}$ ), vencido pelo grupo Pátria Investimentos e administrado pela Entrevias, conforme já apontado anteriormente neste texto. Convém indicar que à época do lançamento do edital, este trecho recebeu o nome de "Lote D" e, depois do leilão realizado e da concessionária vencedora anunciada, passou a ser chamado pelo governo do estado de São Paulo de "Lote 28".

As rodovias referentes a este lote não são contínuas e o lote engloba dois trechos distintos: um ao Norte (que estava sob concessão da Vianorte desde 1998 e cujo contrato se encerrou em 2018) e outro ao Sul (que compreende trecho da SP-333 e que foi entregue à concessão pela primeira vez), conforme pode ser visto na figura 2 (excerto da apresentação "Novas Concessões de Rodovias Estaduais de São Paulo", realizada pelo governo paulista em Audiência Pública do dia 26 de janeiro de 2016). 
Programa de concessão de rodovias em São Paulo e novos agentes econômicos do período contemporâneo. Uma leitura geográfica do planejamento governamental e dos repasses de ISSQN aos pequenos municípios

Figura 2 - São Paulo. Estrutura de concessões de rodovias em São Paulo (Lote D), 2016.

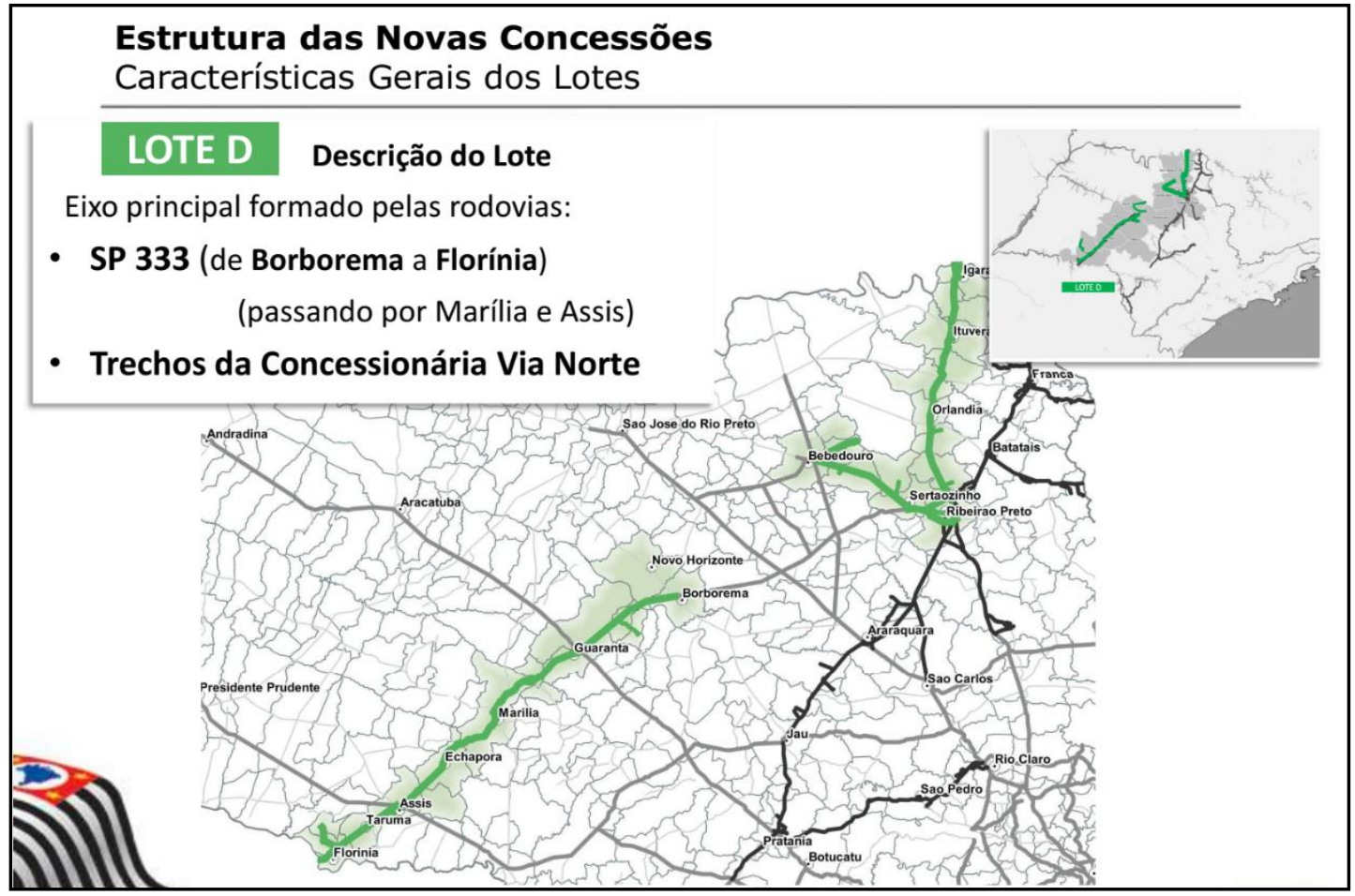

Fonte - São Paulo (2016).

As cobranças de pedágio tiveram início em maio de 2018, no trecho Norte, que compreende o perímetro de $299 \mathrm{~km}$ entre os municípios de Bebedouro, Sertãozinho, Ribeirão Preto e Igarapava e em outubro de 2018, no trecho Sul, compreendido entre os municípios de Borborema e Florínea.

O lote rodoviário da Entrevias cruza as microrregiões de Assis, Borborema, Marília, Ituverava, Pongaí, São Joaquim da Barra, Sertãozinho, Novo Horizonte e Ribeirão Preto. Podemos dizer que um dos focos principais da empresa concessionária é apostar na rentabilidade do projeto de concessão a longo prazo, amparando-se na perspectiva de expansão do agronegócio na região e no aumento do fluxo de veículos nas praças de pedágio das rodovias - conforme o governo do estado de São Paulo, havia uma estimativa do VDM (Volume Diário Médio) de 91 mil veículos passando nas 8 praças de pedágios em 2017. Ademais, ainda segundo dados do governo paulista, a economia da região é predominantemente voltada à agricultura, silvicultura e exploração florestal. Outros setores representativos são os de i) construção, ii) alimentos e bebidas e iii) transportes e armazenagem. A projeção de crescimento esperado em cada um desses setores durante os 30 anos de concessão é de: $86 \%$ em "agricultura, silvicultura e exploração florestal", $144 \%$ no segmento "construção", $54 \%$ no setor de "alimento e bebidas" e $58 \%$ em "transportes e armazenagem". Além disso, em importantes municípios da região se estima o crescimento de setores distintos: $401 \%$ - Aparelhos e instrumentos médico hospitalares (em Novo Horizonte), $284 \%$ - Máquinas, aparelhos e materiais elétricos (em Bauru), 256\% - Máquinas e equipamentos (em Marília), 109\% - Pecuária e Pesca (em Lins) e 98\% Pecuária e Pesca - (em Assis) (SÃO PAULO, 2016).

Como já dissemos, aos municípios lindeiros às rodovias cabem $5 \%$ das receitas bruta mensais auferidas pela concessionária referentes aos repasses de Imposto Sobre Serviço de Qualquer Natureza (ISSQN). Neste ponto chamamos atenção porque no caso do Lote D o trecho Sul (trecho da SP-333) não fazia parte da antiga concessão que era administrada pela empresa Vianorte (concessão iniciada em 1998 e concluída em 2018), ou seja, os municípios lindeiros ao trecho da SP-333, concedida novamente no leilão de 2017, vencido pelo grupo Pátria Investimentos e cuja administração está sob responsabilidade da Entrevias, passaram, desde 2018, a receber um aporte de recursos em suas receitas correntes que até então não tinham. Já os municípios do trecho Norte continuaram a receber tais repasses de ISSQN (tabela 1). Os municípios são: i) Trecho Norte: Aramina, Bebedouro, Buritizal, Guará, Igarapava, Ituverava, Jardinópolis, Orlândia, Pitangueiras, Pontal, Ribeirão Preto, Sales

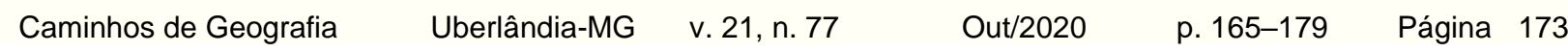


Programa de concessão de rodovias em São Paulo e novos agentes econômicos do período contemporâneo. Uma leitura geográfica do planejamento governamental e dos repasses de ISSQN aos pequenos municípios

Fabricio Gallo

Oliveira, São Joaquim da Barra e Sertãozinho; ii) Trecho Sul: Assis, Borborema, Cafelândia, Cruzália, Echaporã, Florínea, Guarantã, Júlio Mesquita, Marília, Novo Horizonte, Pedrinhas Paulista, Platina, Pongaí, Tarumã e Viradouro.

Tabela 1 - São Paulo. Repasses de ISSQN realizados por concessionárias de rodovias aos municípios do chamado Lote D.

\begin{tabular}{|c|c|c|c|c|c|c|c|c|}
\hline \multirow{2}{*}{ Municípios } & \multirow{2}{*}{ População } & \multicolumn{7}{|c|}{ Repasses de ISSQN (por anos selecionados e em $\mathbf{R} \$^{*}$ ) } \\
\hline & & 2012 & 2013 & 2014 & 2015 & 2016 & 2017 & 2018 \\
\hline \multicolumn{9}{|c|}{ Trecho Norte (sob regime de concessão desde 1998) } \\
\hline Aramina & 5.585 & 1.035 .757 & 1.167 .483 & 1.226 .210 & 1.236 .258 & 1.283 .201 & 1.329 .158 & 1.118 .300 \\
\hline Bebedouro & 77.436 & 294.099 & 321.545 & 340.140 & 351.727 & 387.358 & 420.759 & 634.718 \\
\hline Buritizal & 4.447 & 383.735 & 432.538 & 454.296 & 458.018 & 475.410 & 492.437 & 414.316 \\
\hline Guará & 21.129 & 945.235 & 1.065 .448 & \begin{tabular}{|l|}
1.119 .043 \\
\end{tabular} & 1.128 .213 & \begin{tabular}{|l|}
1.171 .053 \\
\end{tabular} & \begin{tabular}{|l|}
1.212 .994 \\
\end{tabular} & 1.020 .564 \\
\hline Igarapava & 30.246 & 579.867 & 653.613 & 686.491 & 692.117 & 718.398 & 744.127 & 641.367 \\
\hline Ituverava & 41.598 & 1.039 .037 & 1.171.180 & 1.230 .093 & 1.240 .173 & \begin{tabular}{|l|}
1.287 .265 \\
\end{tabular} & 1.333 .367 & 1.121 .841 \\
\hline Jardinópolis & 43.774 & 1.401 .097 & 1.595 .290 & \begin{tabular}{|l|}
1.691 .723 \\
\end{tabular} & 1.659 .591 & 1.659 .383 & \begin{tabular}{|l|}
1.753 .485 \\
\end{tabular} & 1.547 .539 \\
\hline Orlândia & 43.687 & 1.225 .864 & 1.395 .769 & \begin{tabular}{|l|}
1.480 .141 \\
\end{tabular} & 1.452 .028 & 1.451 .846 & 1.534 .178 & 1.309 .477 \\
\hline Pitangueiras & 39.349 & 808.773 & 884.249 & 935.385 & 967.251 & 1.065 .235 & 1.157 .088 & 955.745 \\
\hline Pontal & 49.047 & 254.168 & 277.887 & 293.957 & 303.971 & 334.764 & 363.630 & 299.796 \\
\hline $\begin{array}{l}\text { Ribeirão } \\
\text { Preto }\end{array}$ & 694.534 & 1.972 .403 & 2.188 .822 & 2.336 .960 & 2.383.316 & 2.479 .492 & 2.626.277 & 2.292 .963 \\
\hline Sales Oliveira & 11.779 & 1.055 .257 & 1.201 .516 & 1.274.146 & 1.249 .945 & 1.249 .789 & 1.320 .663 & 1.127 .237 \\
\hline São J. Barra & 51.447 & 1.039 .979 & 1.175 .504 & \begin{tabular}{|l|}
1.237 .934 \\
\end{tabular} & 1.238 .702 & \begin{tabular}{|l|}
1.272 .849 \\
\end{tabular} & 1.325 .503 & 1.119 .575 \\
\hline Sertãozinho & 124.453 & 1.470 .707 & 1.613 .654 & 1.726.476 & 1.789 .555 & \begin{tabular}{|l|}
1.897 .217 \\
\end{tabular} & 2.015 .021 & 1.788 .827 \\
\hline \multicolumn{9}{|c|}{ Trecho Sul (sob regime de concessão desde 2017) } \\
\hline Assis & 103.666 & - & - & - & - & - & - & 103.017 \\
\hline Borborema & 15.925 & - & - & - & - & - & - & 39.589 \\
\hline Cafelândia & 17.689 & - & - & - & - & - & - & 18.195 \\
\hline Cruzália & 2.100 & - & - & - & - & - & - & 19.292 \\
\hline Echaporã & 6.141 & - & - & - & - & - & - & 136.906 \\
\hline Florínea & 2.699 & - & - & - & - & - & - & 97.823 \\
\hline Guarantã & 6.654 & - & - & - & - & - & - & 190.228 \\
\hline $\begin{array}{l}\text { Júlio } \\
\text { Mesquita }\end{array}$ & 4.752 & - & - & - & - & - & - & 32.191 \\
\hline Marília & 237.130 & - & - & - & - & - & - & 344.543 \\
\hline $\begin{array}{l}\text { Novo } \\
\text { Horizonte }\end{array}$ & 40.680 & - & - & - & - & - & - & 18.655 \\
\hline $\begin{array}{l}\text { Pedrinhas } \\
\text { Paulista }\end{array}$ & 3.085 & - & - & - & - & - & - & 47.230 \\
\hline Platina & 3.521 & - & - & - & - & - & - & 8.584 \\
\hline Pongaí & 3.432 & - & - & - & - & - & - & 55.834 \\
\hline Tarumã & 14.812 & - & - & - & - & - & - & 87.435 \\
\hline Viradouro & 18.775 & - & - & - & - & - & - & 589.297 \\
\hline
\end{tabular}

Fonte dos dados brutos - ARTESP. Organização do autor.

*Observação: os valores apontados são os valores correntes e não sofreram a correção monetária do período.

Nesta tabela 1 fica perceptível que os municípios do trecho Sul tiveram o incremento em suas receitas correntes dos valores repassados pela concessionária Entrevias a título de ISSQN a partir de outubro de 2018 (quando o pedágio neste trecho começou a ser efetivamente cobrado), ao passo que os municípios do trecho Norte já recebiam os repasses de ISSQN desde o início da primeira concessão à Vianorte, no ano de 1998. Isso, sem dúvida alguma, é interessante para os municípios do trecho Sul que passam a receber recursos pelo simples fato da rodovia que cruza seus territórios ter sido concedida à iniciativa privada.

Questão relevante é apontar que para os municípios pequenos (entendidos aqui como aqueles com até 20.000 habitantes) este repasse é mais importante ainda. Na tabela 2 destacamos os municípios que se encaixam neste estrato populacional. 
Programa de concessão de rodovias em São Paulo e novos agentes econômicos do período contemporâneo. Uma leitura geográfica do planejamento governamental e dos repasses de ISSQN aos pequenos municípios

Fabricio Gallo

Tabela 2 - São Paulo. Dados de participação do ISSQN de concessão de rodovias nas receitas correntes dos pequenos municípios do chamado Lote $D$.

\begin{tabular}{c|c|c|c|c|c|c}
\hline \multirow{2}{*}{$\begin{array}{c}\text { Municípios } \\
\text { (de até }\end{array}$} & Pop. & $\begin{array}{c}\text { Impostos, } \\
\text { Taxas e } \\
\text { 20.000 hab.) } \\
\text { Contribuições } \\
\text { de Melhoria }\end{array}$ & IPTU Total & $\begin{array}{c}\text { ISSQN } \\
\text { Total }\end{array}$ & $\begin{array}{c}\text { ISSQN de } \\
\text { repasse de } \\
\text { concessão } \\
\text { de } \\
\text { rodovias }\end{array}$ & $\begin{array}{c}\text { \% do ISSQN } \\
\text { de repasse de } \\
\text { concessão de } \\
\text { rodovias no } \\
\text { ISSQN Total }\end{array}$ \\
\hline
\end{tabular}

Trecho Norte (sob regime de concessão desde 1998)

\begin{tabular}{|c|c|c|c|c|c|c|}
\hline Aramina & 5.585 & $--^{*}{ }^{*}$ & --- & --- & 1.118 .300 & --- \\
\hline Borborema & 15.925 & 7.364 .063 & 3.085 .830 & 1.808 .238 & 39.589 & 2,19 \\
\hline Buritizal & 4.447 & 2.046 .463 & 219.283 & 1.215 .790 & 414.316 & 34,08 \\
\hline $\begin{array}{l}\text { Sales } \\
\text { Oliveira }\end{array}$ & 11.779 & 7.145 .854 & 2.212 .886 & 2.516 .202 & 1.127 .237 & 44,80 \\
\hline \multicolumn{7}{|c|}{ Trecho Sul (sob regime de concessão desde 2017) } \\
\hline Cafelândia & 17.689 & 6.176 .694 & 1.499 .268 & 2.333 .789 & 18.195 & 0,78 \\
\hline Cruzália & 2.100 & 868.512 & 195.409 & 196.380 & 19.292 & 9,82 \\
\hline Echaporã & 6.141 & 1.597.119 & 435.472 & 604.363 & 136.906 & 22,65 \\
\hline Florínea & 2.699 & 2.429 .171 & 231.354 & 811.505 & 97.823 & 12,05 \\
\hline Guarantã & 6.654 & 2.223 .210 & 334.821 & 748.278 & 190.228 & 25,42 \\
\hline $\begin{array}{l}\text { Júlio } \\
\text { Mesquita }\end{array}$ & 4.752 & 696.026 & 63.977 & 314.665 & 32.191 & 10,23 \\
\hline $\begin{array}{l}\text { Pedrinhas } \\
\text { Paulista }\end{array}$ & 3.085 & 1.192 .116 & 465.530 & 310.790 & 47.230 & 15,20 \\
\hline Platina & 3.521 & 1.224 .086 & 232.070 & 460.771 & 8.584 & 1,86 \\
\hline Pongaí & 3.432 & 1.344 .624 & 196.076 & 788.577 & 55.834 & 7,08 \\
\hline Tarumã & 14.812 & 7.086 .593 & 2.317 .128 & 2.513 .255 & 87.435 & 3,48 \\
\hline Viradouro & 18.775 & 7.917 .574 & 2.918 .780 & 1.521 .523 & 589.297 & 38,73 \\
\hline
\end{tabular}

Fonte dos dados brutos - ARTESP e FINBRA - Finanças do Brasil - Dados Contábeis dos Municípios. Organização do autor.

*Observação: os dados das receitas correntes do município de Aramina não constam na base do FINBRA e, por isso, não foram puderam ser coletados para fins de comparação.

Nota-se que em alguns municípios a relevância do repasse de ISSQN oriundo exclusivamente da concessionária é tanta que este valor chega a representar $22,6 \%, 25,4 \%, 34,0 \%, 38,7 \%, 44,8 \%$ do valor total do ISSQN arrecadado nos municípios de Echaporã, Guarantã, Buritizal, Viradouro e Sales de Oliveira, respectivamente. O ISSQN é o segundo principal imposto da Receita Tributária das Prefeituras (que é uma arrecadação exclusiva deste ente federado), ficando atrás apenas do IPTU. A Receita Tributária, junto com a Receita de Contribuições, a Receita Patrimonial e as Transferências Correntes compõem a Receita Corrente dos Municípios no Brasil.

\section{CONSIDERAÇÕES FINAIS}

A partir do que apresentamos neste artigo, podemos, por fim, sugerir que a lógica da concessão de infraestruturas e serviços públicos incentivada pelo estado de São Paulo se reinventa e se amplia constantemente.

Ao tratar da escala do governo federal, Brandão (2019, p. 261) nos lembra que "após o impeachment de Dilma, os processos neoliberalizantes se estendem e arraigam-se, em mais uma rodada de liberar o mercado para funcionar sem peias, em um momento de re-des-construção institucional e de ataque à democracia". Esta prática reproduz aquilo que Ribeiro (1998) chamou de paradigma administrativo, entendido como proposições no âmbito do próprio Estado, que teriam de cunho neoliberal e que buscam agilizar reformas institucionais com as orientações provenientes da lógica empresarial.

Em julho de 2019 um amplo catálogo de oportunidades de investimentos, por meio de concessões e PPPs, estava disponibilizado pelo governo estadual paulista, sendo que a carteira de projetos engloba itens como: Concessão de Linhas do Metrô; Projetos em Habitação; Concessão de Aeródromos e

$\begin{array}{lllll}\text { Caminhos de Geografia } \quad \text { Uberlândia-MG } & \text { v. 21, n. } 77 \quad \text { Out/2020 } & \text { p. 165-179 Página } 175\end{array}$ 
Programa de concessão de rodovias em São Paulo e novos agentes econômicos do período contemporâneo. Uma leitura geográfica do planejamento governamental

Aeroportos Regionais; Concessão de Rodovias e das Marginais dos Rios Tietê e Pinheiros; Concessão do sistema de Travessias Litorâneas; Concessão do Sistema Integrado Metropolitano da Região Metropolitana da Baixada Santista e do Serviço Rodoviário Intermunicipal de Transporte de Passageiros do estado de São Paulo; Concessão dos Sistemas Produtores São Lourenço e Alto Tietê; Concessão do Novo Entreposto de Abastecimento Público de São Paulo; Concessão dos Parques de Campos do Jordão, da Cantareira, Alberto Löfgren, do Jardim Zoológico e Jardim Botânico; Concessão administrativa da Fábrica de Hemoderivados do Estado de São Paulo e da FURP - Planta de Produção Américo de Brasiliense; entre outros.

Se em meados da década de 1990 era mais que fundamental a transferência da gestão das rodovias à iniciativa privada, sempre através do discurso da falta de dinheiro por parte do Estado, esse modelo permanece atual e atuante (inclusive como novos agentes participando deste processo, tais como os Fundos de Investimentos). Com a situação econômica brasileira em baixa, num espírito de crise generalizada dos setores e principalmente do Estado, no qual o discurso se volta completamente ao enxugamento da máquina pública, as concessões, parcerias público-privadas ou as privatizações, ganham espaço entre a classe política.

Considerando-se o processo de concessão de rodovias à iniciativa privada, pode-se dizer que, desta forma, algumas áreas do território estadual paulista, em razão de sua maior densidade técnica, isto é, em razão dos diversos graus de artifício de determinado ponto do território (SANTOS, 2002) tornam-se distintas em detrimento de outras já que nem todos os 645 municípios paulistas têm em seus territórios rodovias concedidas à iniciativa privada e, portanto, não recebem o incremento "extra" de ISSQN em suas receitas tributárias. Não estamos aqui defendendo o aumento das concessões para ampliar dos repasses de ISSQN a um número maior de municípios, ao contrário, entendemos que a interpretação teórico-geográfica da liberação desses recursos sugere que há uma diferenciação entre os entes de mesmo nível subnacional, tendo em vista que o princípio federativo fundamental da isonomia não é assegurado aos municípios, uma vez que nem todos são contemplados com determinados tipos de recursos. Acarreta-se, com isso, um certo nível de desigualdade socioespacial oriundo dos diferentes níveis de densidade técnica no território paulista.

No que diz respeito às rodovias, (foco central apresentado neste trabalho) o aumento das concessões e consequentemente das praças de pedágio, aparentemente se torna um ótimo negócio a quase todos os agentes desse processo. Para o Estado há uma redução significativa com as despesas empregadas com infraestrutura de transportes, além de um retorno financeiro via ônus fixo, este estipulado em contrato como $3 \%$ da arrecadação bruta proveniente dos pedágios (isto quando o estado não abre mão para garantir o equilíbrio financeiro da concessionária). As empresas concessionárias aumentam suas receitas através da implantação dos pedágios e assim garantem seu lucro a longo prazo (quase que sem risco algum). Os municípios lindeiros recebem o repasse na forma de ISSQN e com o aumento da arrecadação ou elevação dos preços dos pedágios, proporcionalmente receberão aumento de repasse. Os únicos insatisfeitos são os usuários que pagam pedágios cada vez mais caros e as Prefeitura dos municípios que não têm rodovias concedidas para receber repasses a mais de ISSQN.

\section{AGRADECIMENTOS}

À FAPESP (Fundação de Amparo à Pesquisa do Estado de São Paulo) que financiou partes desta pesquisa através da modalidade "Auxílio Regular à Pesquisa".

\section{REFERÊNCIAS BIBLIOGRÁFICAS}

ANBIMA - Associação Brasileira das Entidades dos Mercados Financeiro e de Capitais. Ranking de Gestores de Fundos de Investimento.

ANTAS JR., R. M. Território e regulação: espaço geográfico, fonte material e não-formal do direito. São Paulo: Associação Editorial Humanitas: Fapesp, 2005.

ARTESP - Agência Reguladora de Serviços Públicos Delegados de Transporte do Estado de São Paulo. Contrato ARTESP no 0352/ARTESP/2017. Contrato de Concessão. Edital de concorrência no 03/2016. 2017. Disponível em: 
Programa de concessão de rodovias em São Paulo e novos agentes econômicos do período contemporâneo. Uma leitura geográfica do planejamento governamental e dos repasses de ISSQN aos pequenos municípios

Fabricio Gallo

http://www.parcerias.sp.gov.br/Parcerias/Documento/Download?codigo=26369. Acesso em: 21 de agosto de 2020.

BONETI, L. Políticas públicas por dentro. Ciudad Autónoma de Buenos Aires: CLACSO; San Pablo: Mercado de Letras, 2017.

BORGES, L. F. X. Project finance e infra-estrutura: descrição e críticas. Revista do BNDES, Rio de Janeiro, v. 5, n. 9, p. [105]-121, jun. 1998.

BRANDÃO, C. A. Mudanças produtivas e econômicas e reconfiguração territorial no Brasil no início do século XXI. Revista Brasileira e Estudos Urbanos e Regionais. São Paulo, vol. 21, n. 2, maio-ago. 2019, pp. 258-279. https://doi.org/10.22296/2317-1529.2019v21n2p258

BRASIL. Senado Federal. Proposta de Emenda à Constituição n ${ }^{57}$, de 2016. Altera os arts. 30, 37, 146, 150, 179 e 195 da Constituição Federal para prever que lei complementar conceituará pequeno Município, poderá disciplinar os princípios da Administração Pública e as normas gerais aplicáveis ao processo administrativo fiscal, à substituição tributária, à moralidade tributária, à eficiência tributária e à vedação de confisco, e ao estabelecimento do estatuto de defesa dos direitos contribuintes; dá nova disciplina ao princípio da anterioridade; elimina a exigência de certidão negativa dos débitos previdenciários para participação em procedimentos licitatórios e contratação com o setor público; e fixa a obrigatoriedade de especificação de tratamento diferenciado e simplificado das microempresas e empresas de pequeno porte no âmbito das normas de caráter geral aplicáveis às empresas. Brasília, 2016. Disponível em: https://www25.senado.leg.br/web/atividade/materias/-/materia/127414. Acesso em: 24 de agosto de 2020 .

CATAIA, M. Território usado e federação: articulações possíveis. Educação \& Sociedade, vol. 34, n. 125, 2013, pp. 1135-1151. https://doi.org/10.1590/S0101-73302013000400007

CVM (Comissão De Valores Mobiliários). Instrução no 555, de 17 de dezembro de 2014. Texto Integral da Instrução CMV № 555. Rio de Janeiro, RJ, Disponível em: http://www.cvm.gov.br/legislacao/instrucoes/inst555.html. Acesso em: 05 de maio de 2019.

FITCHRATINGS. Fitch Afirma Ratings 'BB' e 'AA(bra)' da 2ª Emissão de Debêntures da Entrevias. 21 de fevereiro de 2019. Disponível em: https://www.fitchratings.com/research/pt/infrastructure-projectfinance/fitch-afirma-ratings-bb-e-aa-bra-da-2a-emissao-de-debentures-da-entrevias-21-02-2019.

Acesso em: 24 de agosto de 2020.

FRITZEN, M. Uso do território e geração hidrelétrica de pequeno porte no Brasil. Dissertação (Mestrado) - Programa de Pós-graduação em Geografia, Instituto de Geociências, Universidade Estadual de Campinas, Campinas, 2017. 168 f. Disponível em http://repositorio.unicamp.br/handle/REPOSIP/330803. Acesso em: 12 de junho de 2019.

GALLO, F. Usos do território e o papel do Estado no Brasil: notas sobre a atuação da Agência Desenvolve SP. GEOUSP: espaço e tempo, v. 21, p. 480-496, 2017. https://doi.org/10.11606/issn.2179-0892.geousp.2017.119737

GOTTMANN, J. A evolução do conceito de território. Boletim Campineiro de Geografia. Vol. 2, n. 3, 2012.

HARVEY, D. A produção capitalista do espaço. São Paulo: Annablume, 2005.

HOHL, V. R. O novo marco regulatório do brasil para os projetos de geração de energia elétrica e sua capacidade de atrair os fundos de pensão para investir no setor objetivando o retorno a longo prazo. Dissertação (Mestrado) - Curso de Programa de Mestrado Profissionalizante, Departamento de Economia, Universidade de Brasília, Brasília, 2012. 88f. Disponível em: http://repositorio.unb.br/handle/10482/13597. Acesso em: 12 de junho de 2019.

LIMONAD, E. Estado, espaço e escala no Brasil. Subsídios para a Reflexão. Scripta Nova. Revista Electrónica de Geografía y Ciencias sociales, № 493 (41), 2014, p. 8.

LOPES, G. N. Serviços de infraestrutura como opção de investimentos para os fundos de pensão brasileiros. Dissertação (Mestrado) - Curso de Programa de Pós-graduação em Desenvolvimento 
Programa de concessão de rodovias em São Paulo e novos agentes econômicos do período contemporâneo. Uma leitura geográfica do planejamento governamental e dos repasses de ISSQN aos pequenos municípios

Fabricio Gallo

Econômico, Instituto de Economia, Universidade Estadual de Campinas, Campinas, 2012, $122 f$. Disponível em: http://repositorio.unicamp.br/ispui/handle/REPOSIP/285847. Acesso em 05 de maio 2019.

MANTOAN, V.; FERNANDES, D. Estrangeiras avaliam novas oportunidades no Brasil. Jornal Valor Econômico. São Paulo, 08 de abril de 2015. Disponível em: https://valor.globo.com/empresas/noticia/2015/04/08/estrangeiras-avaliam-novas-oportunidades-nobrasil.ghtml. Acesso em 20 de agosto de 2020.

OLIVEIRA, C. O papel das concessões de rodovias na normatização do território brasileiro e suas relações com a circulação. 2016. 321f. Tese (Doutorado em Geografia) - Faculdade de Ciências e Tecnologia, Universidade Estadual Paulista "Júlio de Mesquita Filho", Presidente Prudente, 2016.

OLIVEIRA, C.; SPOSITO, E. S. Estado de São Paulo: dinâmica econômica, concessões rodoviárias e análise dos indicadores PIB e IDH. Geografia em atos, n. 7, v.1. Presidente Prudente, 2007.

PASTI, A.; SILVA BERNARDES, A. M. O mercado de capitais e os círculos de informações financeiras no território brasileiro. Confins (Paris), v. 2013, p. 2, 2013. https://doi.org/10.4000/confins.8653

PINTO, E. C.; BALANCO, P. Estado, bloco no poder e acumulação capitalista: uma abordagem teórica. Revista de Economia Política, vol. 34, oㅜ 1 (134), pp. 39-60, janeiro-março/2014. https://doi.org/10.1590/S0101-31572014000100003

RIBEIRO, A. C. T. Relações sociedade-Estado: elementos do paradigma administrativo. Cadernos IPPUR. Rio de Janeiro: IPPUR/UFRJ, ano 12, n. 2, pp. 107-125, ago-dez., 1998.

RIBEIRO, T. B.; TONETO JÚNIOR, R. As receitas tributárias das praças de pedágio e as finanças públicas municipais: uma análise do esforço fiscal no estado de São Paulo. Planejamento e Políticas Públicas (PPP), Brasília, n. 27, p. 117-139, jun./dez. 2004.

SÃO PAULO (Estado). São Paulo segue em frente - Mobilidade. Novas Concessões de Rodovias no Estado de São Paulo. Audiência Pública. São Paulo, jan. 2016. Disponível em: www.parcerias.sp.gov.br/Parcerias/Documento/Download?codigo=2061 (acessado em 20 de janeiro de 2020).

SÃO PAULO (Estado). Decretos. Decreto no 63.489, de 14 de junho de 2018 [Institui Grupo de Trabalho com o objetivo de realizar estudos alusivos ao projeto Macroanel Rodoviário Paulista, a fim de apresentar as alternativas de traçado com os respectivos riscos e os planos de ação para sua implantação pelo Governo do Estado de São Paulo]. Diário Oficial do Estado de São Paulo. Volume 128, no 109, São Paulo, sexta-feira, 15 de junho de 2018, 2018a. Disponível em: http://dobuscadireta.imprensaoficial.com.br/default.aspx? DataPublicacao=20180615\&Caderno=DOEI\&NumeroPagina=1. Acessado em: 21 de agosto de 2020.

SÃO PAULO (Estado). Atos do governador. Ata. [Ata da 235ª Reunião Ordinária do Conselho Diretor do Programa Estadual de Desestatização, instituído por força da Lei Estadual 9.361-96]. Diário Oficial do Estado de São Paulo. Volume 128, no 167, São Paulo, quinta-feira, 6 de setembro de 2018, 2018b. Disponível

em: https://www.imprensaoficial.com.br/Certificacao/GatewayCertificaPDF.aspx?notarizacaolD=ca2fb04b2989-4d8c-813b-4fb15aa40ec2. Acessado em: 21 de agosto de 2020.

SANTOS, M. A natureza do espaço. Técnica e tempo, razão e emoção. São Paulo: EDUSP, 2002.

Da política dos Estados à política das empresas. Cadernos da Escola do Legislativo. Belo Horizonte, 3(6): 3-191, jul/dez. 1997.

O retorno do território. In: SANTOS, M.; SOUZA, M. A. A. de; SILVEIRA, M. L. (org). Território: globalização e fragmentação. São Paulo: Anpur/Hucitec, 1994, p. 15-20.

SILVA BERNARDES, A. M. Círculos de informações, urbanização e usos do território. Revista da ANPEGE, v. 8, p. 3-15, 2012. https://doi.org/10.5418/RA2012.0810.0001 
SILVEIRA, M. L. O lugar defronte os oligopólios. In: DANTAS, A.; TAVARES, M.A.A. (Org.). Lugarmundo: perversidades e solidariedades. Encontros com o pensamento de Milton Santos. Natal: EDUFRN, 2011. p. 79-100.

TOMAZELA, J. M. Alckmin suspende lote B da nova concessão de rodovias. O Estado de São Paulo. São Paulo, 26 de fevereiro de 2016. Disponível em: https://saopaulo.estadao.com.br/noticias/geral,alckmin-suspende-lote-b-da-nova-concessao-derodovias, 10000018467 . Acesso em 21 de agosto de 2020.

VAINER, C. B. Lugar, região, nação, mundo: explorações históricas do debate acerca das escalas de ação política. Revista Brasileira de Estudos Urbanos e Regionais, v.8, n.2, 2006, pp. 9-29. https://doi.org/10.22296/2317-1529.2006v8n2p9

Recebido em: 04/02/2020

Aceito para publicação em: 26/08/2020 